\title{
Effective desalination by capacitive deionization with functional graphene nanocomposite as novel electrode material
}

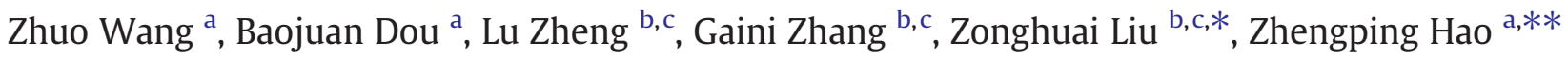 \\ ${ }^{a}$ Research Center for Eco-Environmental Sciences, Chinese Academy of Sciences, Beijing 100085, China \\ b Key Laboratory of Applied Surface and Colloid Chemistry (Shaanxi Normal University), Ministry of Education, Xi'an, 710062, China \\ c School of Chemistry and Materials Science, Shaanxi Normal University, Xi'an, 710062, China
}

\section{A R T I C L E I N F O}

\section{Article history:}

Received 1 April 2012

Received in revised form 29 May 2012

Accepted 29 May 2012

Available online 18 June 2012

\section{Keywords:}

Reduced graphite oxide-resol (RGO-RF)

Electrosorption

Capacitive deionization (CDI)

Desalination

\begin{abstract}
A B S T R A C T
In this work, functional graphene nanocomposite (reduced graphite oxidate-resol like material, named RGO-RF) was successfully synthesized and used as electrode in capacitive deionization (CDI) process. The porosity, morphology and electrochemical characteristics of RGO-RF were confirmed by $\mathrm{N}_{2}$ adsorption-desorption curve, transmission electron microscopy and cyclic voltammetry, respectively. Further, the deionization performances of the RGO-RF electrode, reduced graphite oxidate (RGO) and activated carbon (AC) were examined for comparison by a lab-scale CDI experimental system. It is found that the RGO-RF shows the best deionization performance among the three target materials, indicating that it is a novel electrode material which has a great potential as effective electrode for CDI. Besides, the electrosorption isotherms and electrosorption kinetics were studied, and it is found that the ion sorption behaviour of RGO-RF follows a Langmuir adsorption isotherm, implying monolayer adsorption.
\end{abstract}

(c) 2012 Elsevier B.V. All rights reserved.

\section{Introduction}

Since the continuous increase of the world's population, the shortage of potable water has become one of the major issues in many countries in the past few decades [1-6]. To address this issue, extensive efforts have been devoted, involving development of new technique to reuse the wastewater and desalination of brackish water as well as the sea water. Currently, there are varieties of approaches for water purification, including ion exchange, electrodialysis, reverse osmosis and distillation, etc. [7-12]. Among all of the alternative approaches for water purification, desalination is a significant choice for producing potable water in many countries of the world, considering that $80 \%$ of our planet is occupied by the sea. However, most traditional desalination technologies are energy and capital intensive, for example, ion exchange produces secondary pollution resulting from the regeneration of resins [11] while electrodialysis, reverse osmosis [13] and distillation [14] are capital and energy intensive and require hard maintenance. Capacitive deionization (CDI), usually called electrosorption somewhere, absorbing ionic species onto the charged porous electrodes for desalination purpose, receives much attention in desalination community in recent years. Specifically, when an external direct voltage $(<2 \mathrm{~V})$ is imposed on the porous electrode, the electrochemical double layer would be formed in the

\footnotetext{
* Corresponding author. Tel.: + 8629 85303701; fax + 862985307774 .

** Corresponding author. Tel./fax: + 861062923564 .

E-mail addresses: zhliu@snnu.edu.cn (Z. Liu), zpinghao@rcees.ac.cn (Z. Hao).
}

solution-electrode interface for holding ions. Once the external power is shorted or even reversed, the adsorbed ions would be released back to solution, resulting in the regeneration. Thus, this process shows the advantages of energy efficiency, high removal efficiency, easy regeneration and low cost over the above mentioned desalination technologies [5].

Basically, the prerequisite for the high removal efficiency of CDI is directly related to the electrode materials, which has high specific surface area for accommodating ions as well as superior conductivity for decreasing the contact resistivity. Up to date, various materials were investigated as CDI electrodes, such as activated carbon (AC), activated carbon composite materials, carbon nanotubes (CNTs), activated carbon cloth (ACC), carbon aerogel and mesoporous carbon (OMC) [5,13-28]. Based on analysing these materials, it is found that a high capacitive electrode should have large specific surface area for ionic accumulation, good electrical conductivity for effective charge holding and suitable pore size. Carbon materials have been extensively studied as electrodes, however most of them have their own disadvantages, for example, activated carbon (AC) has large surface area, the pore size is not favourable for electrosorption, and carbon nanotubes (CNTs), from the commercial application of view, are too expensive. So, it is necessary and desirable to seek and develop a new type of material as effective CDI electrodes.

Graphene, a two-dimensional carbon material with unique mechanic and electronic properties, offers promising properties, and $\mathrm{sp}^{2}$ boned carbon material, has drawn extensive attention since 2004 due to its unique physical and chemical properties [29-32]. The recent dramatic breakthrough in chemical methodology makes it 
easy to result in large-scale production which widely spans the graphene research not only carried out in laboratory, but also commercialized somewhere. As a low dimensional material, graphene has a huge theoretical specific surface area of $2600 \mathrm{~m}^{2} / \mathrm{g}$, which is twice than that of the finely divided AC [33]. On the other hand, graphene presents an excellent electrical conductivity of $7200 \mathrm{~S} / \mathrm{m}$ at room temperature [34]. These intriguing properties enable graphene to be used as electrode materials for energy storage device as well as CDI due to their similar working principle. However, although graphene was successfully proposed and developed as novel electrodes for $\mathrm{CDI}[1,35,36]$, the corresponding functional composites are seldom explored anywhere up to now. Because functional groups coupled with graphene have the advantage of both enlarging the specific surface area and enhancing the adsorption capability of graphene, it is worth conducting such a study to strengthen our basic understanding in application of graphene and graphene nanocomposite as electrode for CDI. In order to make the research of functional graphene deep and broadly going, functional graphene (RGO-RF) was synthesized and the electrosorptive properties were investigated for $\mathrm{CDI}$.

In this work, the reduced graphite oxidate-resol like material (RGO-RF) was synthesized as electrodes for CDI to examine its electrosorption performance by comparing with reduced graphite oxidate (RGO) and commercial AC under the same experimental conditions. Besides, the working conditions, electrosorption isotherms and electrosorption kinetics in terms of RGO-RF based CDI were investigated as well. All of these are very important to develop new electrode materials and effective technology for desalination.

\section{Experimental}

\subsection{Preparation of $R G O$ and $R G O-R F$ materials}

Graphite oxidate (GO) was synthesized by a modified Hummers method [37]. The detailed information was described in the Supporting Information (SI).

RGO-RF was prepared by the modified method reported by Worsley's group [38]. Typically, $2 \mathrm{mg} / \mathrm{mL}$ of GO suspension was thoroughly dispersed in deionized water by sonication for $1.5 \mathrm{~h}$. Then, resorcinol (R), formaldehyde (F) and sodium carbonate catalyst (C) were added to the mixture altogether. The ratio of R:F:C was 200:400:1, according to the illustration reported [38]. Once GO was dispersed, resorcinol $(1.235 \mathrm{~g})$, formaldehyde $(1.791 \mathrm{~g})$ and sodium carbonate catalyst $(5.95 \mathrm{mg}$ ) were added to the solution. Following, the solution was transferred to a $100 \mathrm{~mL}$ Teflon-lined autoclave and maintained at $85^{\circ} \mathrm{C}$ for 3 days. After that, the resulting mixture was washed with acetone for 3 days in order to remove the water from the pores of the mixture. Successfully, the mixture was reduced by calcination at $900{ }^{\circ} \mathrm{C}$ under $\mathrm{N}_{2}$ atmosphere, resulting in the reduced graphite oxidate-resol like material, named RGO-RF.

\subsection{Preparation of $C D I$ electrodes}

The carbon materials (RGO-RF, RGO and AC), and polytetrafluoroethene (PTFE) as binder, were employed to fabricate the electrodes and their percentage were $80 \%$ and $20 \%$ respectively. Each electrode was about $70 \mathrm{~mm}$ wide $\times 140 \mathrm{~mm}$ long $\times 0.3 \mathrm{~mm}$ thick, and had a flow-through hole with a diameter of $4 \mathrm{~mm}$. Ethanol $(10-20 \mathrm{~mL})$ was added dropwise to the mixture and then the mixture was pressed on graphite sheet and then dried for $8 \mathrm{~h}$ at $50{ }^{\circ} \mathrm{C}$. Finally, the electrodes were assembled into a CDI unit cell.

\subsection{Characterizations}

The structures of the electrode materials were characterized by transmission electron microscopy (TEM, JEOL 3010). The X-ray diffraction (XRD) patterns of all samples were measured on a Rigaku powder diffractometer (D/MAX-RB) using $\mathrm{Cu} K \alpha$ radiation $(\lambda=0.15418 \mathrm{~nm})$ at a scanning rate of $4^{\circ} / \mathrm{min}$ in $2 \theta=10-80^{\circ}$. Adsorption and desorption isotherms of nitrogen were measured with a NOVA 1200 gas sorption analyser at liquid nitrogen temperature $\left(-196^{\circ} \mathrm{C}\right)$. Before the measurements, the samples were degassed under vacuum condition at $300{ }^{\circ} \mathrm{C}$ for $3 \mathrm{~h}$. The Brunauer-Emmett-Teller (BET) method was utilized to calculate the specific surface area using adsorption data acquired at a relative pressure $\left(\mathrm{P} / \mathrm{P}_{0}\right)$ range of $0.5-0.25$. The total pore volume was estimated from the amount adsorbed at a relative pressure of about 0.99 . The pore size distribution curves were calculated from the analysis of the desorption branch of the isotherm based on the Barrett-Joyner-Halenda (BJH) algorithm. The micropore volume and micropore surface area were estimated by a t-plot method.

\subsection{Electrochemical characterization}

Cyclic voltammetry (CV) measurements of RGO-RF, RGO and AC were performed on an electrochemical workstation (CHI 600 D, Shanghai $\mathrm{CH}$ Instrument Company, China) with a typical three-compartment cell at ambient temperature. The as-synthesized electrode materials, a Pt wire electrode and an $\mathrm{Ag} / \mathrm{AgCl}$ electrode were used as working electrode, counter electrode and reference electrode, respectively. The electrolyte was $1 \mathrm{M} \mathrm{NaCl}$ aqueous solution and the sweep potential range was adjusted from $-1 \mathrm{~V}$ to $0 \mathrm{~V}$ (vs $\mathrm{Ag} / \mathrm{AgCl}$ electrode). The capacitance was calculated from the current-voltage curves according to the following equation:

$C=\frac{\int I d V}{v m V}$

where $\mathrm{C}$ is the specific capacitance $(\mathrm{F} / \mathrm{g})$, I is the response current $(\mathrm{A}), \mathrm{V}$ is the potential $(\mathrm{V}), v$ is the potential scan rate $(\mathrm{mV} / \mathrm{s})$, and $\mathrm{m}$ is the mass of the electroactive materials in the electrodes $(\mathrm{g})$.

\subsection{Electrosorption experiment}

Electrosorptive removal of $\mathrm{NaCl}$ by $\mathrm{CDI}$ was measured using a continuous recycling system including a CDI unit cell, a peristaltic pump, a power supply and a conductivity monitor. In a typical experiment, the $\mathrm{NaCl}$ with initial conductivity of $55 \mu \mathrm{S} / \mathrm{cm}$ and volume of $200 \mathrm{~mL}$ was employed as feed solution. The mass of the electrodes was $1.5 \mathrm{~g}$. The flow rate was $20 \mathrm{~mL} / \mathrm{min}$ and different voltage was applied on the CDI unit. The variation of solution conductivity was monitored instantly by a multi-function conductivity meter (DDS-11A LiDa instrument). Accordingly, the correlation of conductivity $(\mu \mathrm{S} / \mathrm{cm})$ and concentration $(\mathrm{mg} / \mathrm{L})$ were calibrated prior to experiment.

In our experiment, the electrosorptive capacity was defined as below,

Electrosorptive capacity $(\mathrm{mg} / \mathrm{g})=\frac{\left(C_{0}-C_{t}\right) V}{M}$

where $\mathrm{C}_{0}$ and $\mathrm{C}_{\mathrm{t}}(\mathrm{mg} / \mathrm{L})$ represent the initial and final $\mathrm{NaCl}$ concentrations, respectively, and $\mathrm{V}$ is the volume of the solution (L), and $\mathrm{M}$ is the mass of electrode $(\mathrm{g})$.

\section{Results and discussion}

Generally speaking, the experimental conditions have a dramatic influence on the characters of the synthesized materials. In our experiment, hydrothermal method was used and then calcined to $900{ }^{\circ} \mathrm{C}$ directly without supercritical method, and it is found that the addition of resorcinol and formaldehyde can make the surface area of the material increase. 


\subsection{Morphology of RGO-RF and GO}

Fig. 1 (a) and (b) shows the TEM images of GO and RGO-RF, respectively. It can be seen from Fig. 1 (a) that the GO sheets show a transparent character. In contrast to Fig. 1 (a), it is noted from Fig. 1 (b) that the RGO is fully covered by resol, incorporated with XRD pattern (Fig.S1), indicating the resol coupled with RGO very well.

The $\mathrm{N}_{2}$ adsorption-desorption isotherm and the pore size distribution of RGO-RF, RGO and AC are presented in Fig. 2 (a) and (b), respectively. RGO-RF adopts clearly a typical type-IV isotherm with a hysteresis loop between the adsorption and desorption branches, integrated with pore size distribution, implying the existence of some mesopores which guarantees a huge space for ion accommodation in CDI process. In the case of $A C$, the curve exhibits a typical , which is the typical characteristic of microporous materials, illustrating that the huge BET surface area of AC is mainly contributed by the micropores and thereby it is not beneficial for ion accessing because the mesopores could be seen as the ion transportation route [25]. The detailed parameters including surface area and pore volume of RGO-RF, RGO and AC are summarized in Table 1. Notably, although the specific surface area of AC is larger than that of RGO-RF, the volume and surface area of micropores associated with RGO-RF are much smaller than that of AC except total pore volume, together with pore size distribution (shown in Fig.2 (b)), indicating the RGO-RF comprises a large fraction of mesopores $(2-50 \mathrm{~nm})$ which is thought to be the optimum pore size for electrosorption in CDI process. Upon this, the surface area and total pore volume of RGO-RF are much larger than the corresponding value of RGO, illustrating that the coupled resol plays a significant role in enhancing the surface area of RGO, resulting in a high electrosorption performance.

\subsection{Electrochemical property}

$\mathrm{CV}$ measurements involving the RGO-RF, RGO and $\mathrm{AC}$ in $1 \mathrm{M} \mathrm{NaCl}$ aqueous solution at various sweep rates (from $10 \mathrm{mV}$ to $100 \mathrm{mV}$ ) from $-1 \mathrm{~V}$ to $0 \mathrm{~V}$ were carried out to examine the electrical double layer formation, from which electrosorption capacitance was calculated (Eq. (1)). Fig. 3 (a) and (b) shows the CV curves of RGO-RF and RGO at different sweep rates and the corresponding specific capacity is presented in Fig. 4. The CV curves of the RGO are asymmetric, with two small peaks located at -0.7 and $-0.3 \mathrm{~V}$, respectively, indicating the presence of electrochemical reactions due to the residual functional groups as a result of incomplete reduction from GO to RGO. Upon dealing with resol, all the CV curves become symmetric (Fig. 3 (a)), regardless of the sweep rate, implying that the electrosorption process is reversible. At the mean time, the symmetric curve shows a smooth shape without presence of any peaks, illustrating that the dealt resol (a)

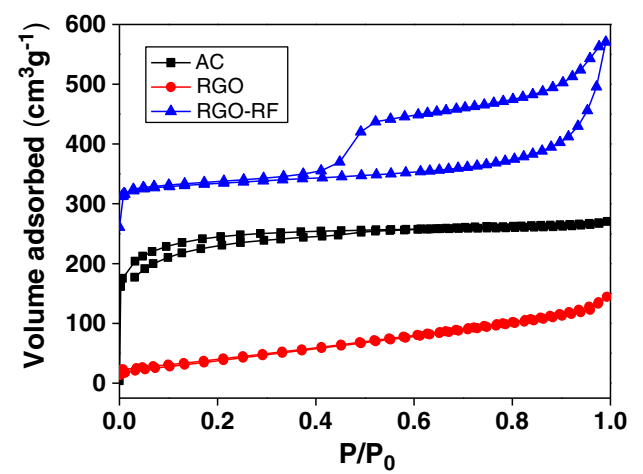

(b)

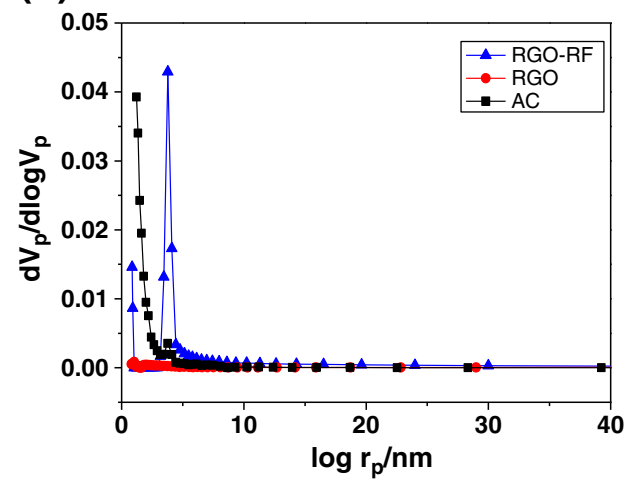

Fig. 2. $\mathrm{N}_{2}$ adsorption-desorption isotherm (a) and pore size distribution (b) of AC, RGO and RGO-RF samples at $77 \mathrm{~K}$.

is beneficial to the decrease of the residual functional groups. Specifically, taking into the sweep rate at $10 \mathrm{mV}$ as an example, the specific capacitance increased greatly from $112 \mathrm{~F} / \mathrm{g}$ for RGO to $135.7 \mathrm{~F} / \mathrm{g}$ for RGO-RF, due to a dramatic rise in the specific surface area. Likewise, the enhancement of specific surface area can account for the increase of the specific capacitance at other sweep rates. In addition, it can be seen that at each sweep rate, the specific capacitance of RGO-RF and $\mathrm{RGO}$ is larger than that of AC, possibly attributed to the small $\mathrm{V}_{\text {micropore }}$ as well as $\mathrm{S}_{\text {micropore }}$ inside the RGO-RF and RGO.

\subsection{Electrosorption performances}

It is known that the CDI process is closely related to the electrical voltage. In our experiment, as expected, high electrical voltage results in high electrosorptive capacity because of strong Coulombic interaction. Fig. 5 shows the electrosorption performance of RGO- (a)

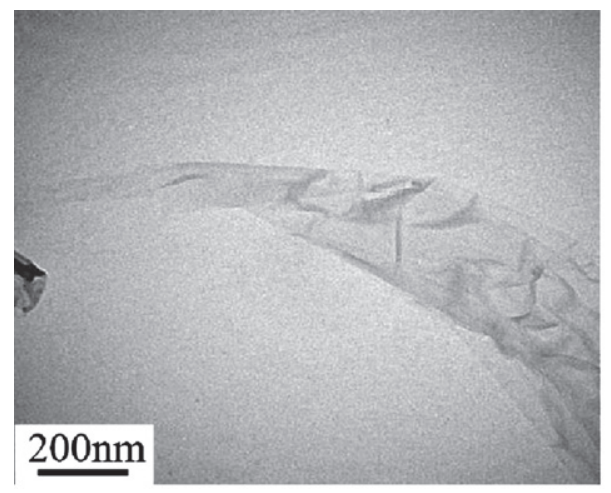

(b)

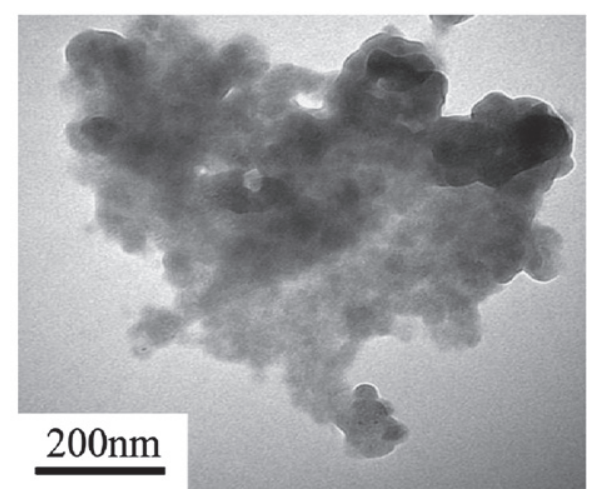

Fig. 1. TEM images of (a) GO and (b) RGO-RF. 
Table 1

Pore parameters of different electrodes from the nitrogen isotherms at $-196{ }^{\circ} \mathrm{C}$.

\begin{tabular}{llllll}
\hline Materials & $\begin{array}{l}\mathrm{S}_{\mathrm{BET}} \\
\left(\mathrm{m}^{2} \mathrm{~g}^{-1}\right)\end{array}$ & $\begin{array}{l}\mathrm{V}_{\text {total }} \\
\left(\mathrm{cm}^{3} \mathrm{~g}^{-1}\right)\end{array}$ & $\begin{array}{l}\mathrm{V}_{\text {micropore }} \\
\left(\mathrm{m}^{3} \mathrm{~g}^{-1}\right)\end{array}$ & $\begin{array}{l}\mathrm{S}_{\text {micropore }} \\
\left(\mathrm{m}^{2} \mathrm{~g}^{-1}\right)\end{array}$ & $\begin{array}{l}\mathrm{D}_{\text {pore size }} \\
(\mathrm{nm})\end{array}$ \\
\hline RGO-RF & 406.4 & 0.3174 & 0.1042 & 226.9 & 3.124 \\
RGO & 137.4 & 0.223 & - & - & 6.502 \\
AC & 836.0 & 0.418 & 0.345 & 754.4 & 2.001 \\
\hline
\end{tabular}

$\mathrm{RF}$ at different electrical voltages and the inset represents the electrosorptive capacity as a function of electrical voltage. With the increase of voltage from $0.5 \mathrm{~V}$ to $2.0 \mathrm{~V}$, the electrosorptive capacity gradually rose from $0.457 \mathrm{mg} / \mathrm{g}$ to $1.424 \mathrm{mg} / \mathrm{g}$ which is higher than the reported $23.18 \mu \mathrm{mol} / \mathrm{g}(1.35 \mathrm{mg} / \mathrm{g})$ [1].

Further, the impact of initial concentrations on electrosorptive performance in association with RGO-RF, RGO and AC electrodes was investigated as well. Fig. 6 shows the conductivity transient in terms of RGO$\mathrm{RF}, \mathrm{RGO}$ and AC electrodes with respect to different initial concentrations, ranging from $25 \mathrm{mg} / \mathrm{L}$ to $65 \mathrm{mg} / \mathrm{L}$ with an interval of 15 and $25 \mathrm{mg} / \mathrm{L}$. Accordingly, the voltage was $2.0 \mathrm{~V}$ and flow rate of $20 \mathrm{~mL} / \mathrm{min}$. Overall, the RGO-RF presents the best electrosorption performance among three target electrodes, regardless of initial concentration. On another hand, with the concentration that increased from $25 \mathrm{mg} / \mathrm{L}$ to $65 \mathrm{mg} / \mathrm{L}$, the electrosorptive capacity of RGO-RF electrode is gradually enhanced from $1.424 \mathrm{mg} / \mathrm{g}$ to $3.229 \mathrm{mg} / \mathrm{g}$, illustrating that the initial concentration has a positive impact on electrosorption performance of RGO-RF. It is likewise in the case of RGO and AC electrode. Table 2 lists the electrosorptive capacity of RGO-RF, RGO and AC electrode under different initial concentrations.

(a)

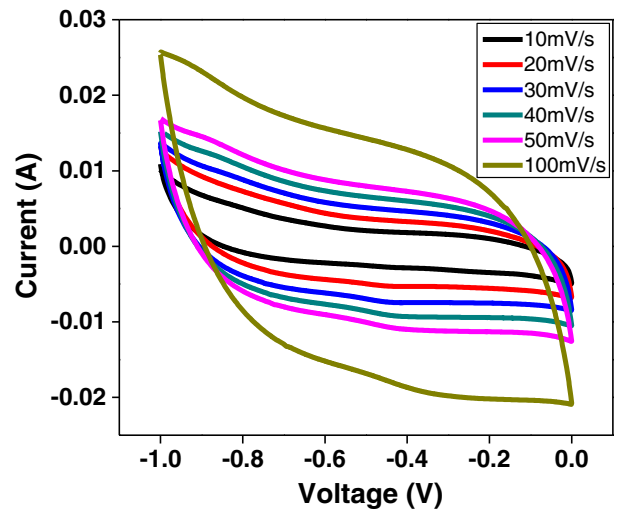

(b)

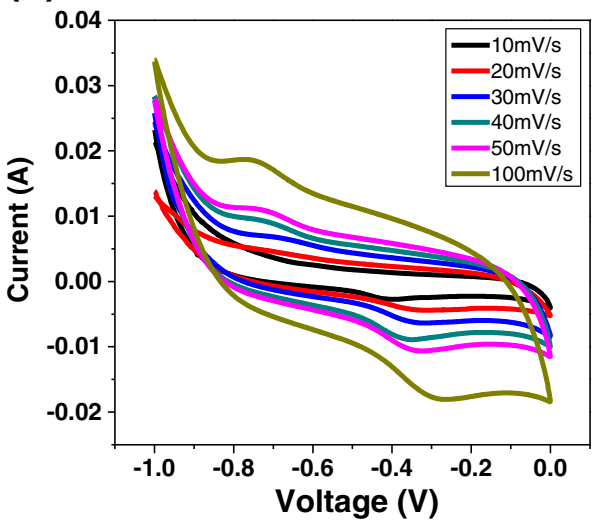

Fig. 3. Cyclic voltammograms of RGO-RF (a) and RGO (b) at different sweep rates (10, $20,30,40,50,100 \mathrm{mV} / \mathrm{s}$ ) in $1 \mathrm{M} \mathrm{NaCl}$ aqueous solution.

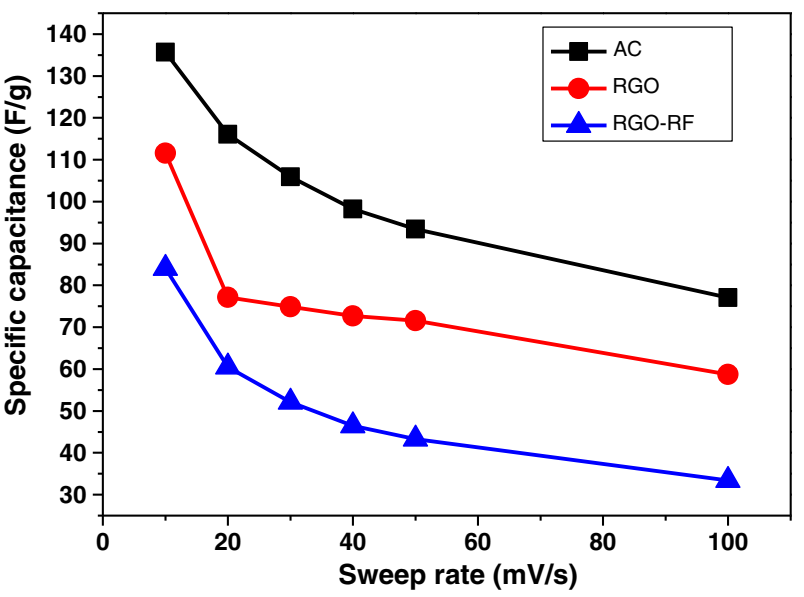

Fig. 4. Specific capacitance of RGO-RF, RGO and $\mathrm{AC}$ in $1 \mathrm{M} \mathrm{NaCl}$ aqueous solution at different sweep rates.

\subsection{Electrosorption isotherms}

To further investigate the electrosorption isotherm of as-prepared RGO-RF, batch electrosorption experiments were carried out at different initial concentrations, involving $50 \mathrm{mg} / \mathrm{L}, 100 \mathrm{mg} / \mathrm{L}, 200 \mathrm{mg} / \mathrm{L}, 300 \mathrm{mg} / \mathrm{L}$, $400 \mathrm{mg} / \mathrm{L}$ and $500 \mathrm{mg} / \mathrm{L}$ with the electrical voltage of $2.0 \mathrm{~V}$ and flow rate of $20 \mathrm{~mL} / \mathrm{min}$. The linearized Langmuir equation (Eq. (3)) and Freundlich equation (Eq. (4)) were employed to simulate the experimental data, which are listed as below:

$1 / \mathrm{Q}=1 / \mathrm{Q}_{\mathrm{m}} \mathrm{KC}+1 / \mathrm{Q}_{\mathrm{m}}$

$\lg \mathrm{Q}=\lg \mathrm{K}+1 / \operatorname{nlg} \mathrm{C}_{\mathrm{e}}$

where $\mathrm{C}$ is the equilibrium concentration ( $\mathrm{mg} / \mathrm{L}$ ), $\mathrm{Q}$ is the amount of adsorbed $\mathrm{NaCl}(\mathrm{mg} / \mathrm{g}), \mathrm{Q}_{\mathrm{m}}$ is the maximum adsorption capacity corresponding to complete monolayer coverage. $\mathrm{K}_{\mathrm{L}}$ is Langmuir constant related to binding energy $(\mathrm{L} / \mathrm{mg}), \mathrm{K}_{\mathrm{F}}$ and $\mathrm{n}$ are the Freundlich constants related to the capacity of adsorbent to adsorb and the tendency of the adsorbate to be adsorbed, respectively.

In order to predict the adsorption efficiency of the process, the dimensionless quantity $(r)$ was calculated by using the following equation:

$r=\frac{1}{1+K_{L} C_{0}}$

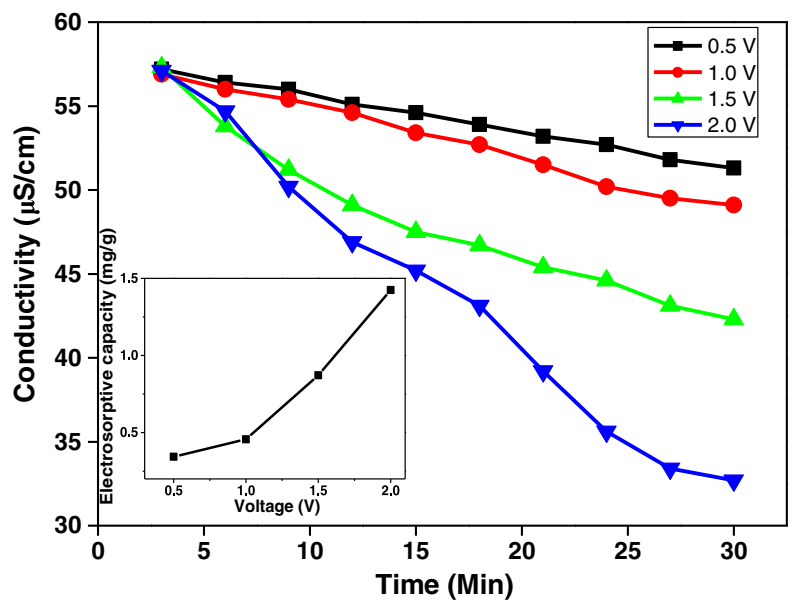

Fig. 5. Electrosorption of $\mathrm{NaCl}$ onto RGO-RF electrode at different electrical voltages. (The inset shows the electrosorptive capacity of RGO-RF) 
(a)

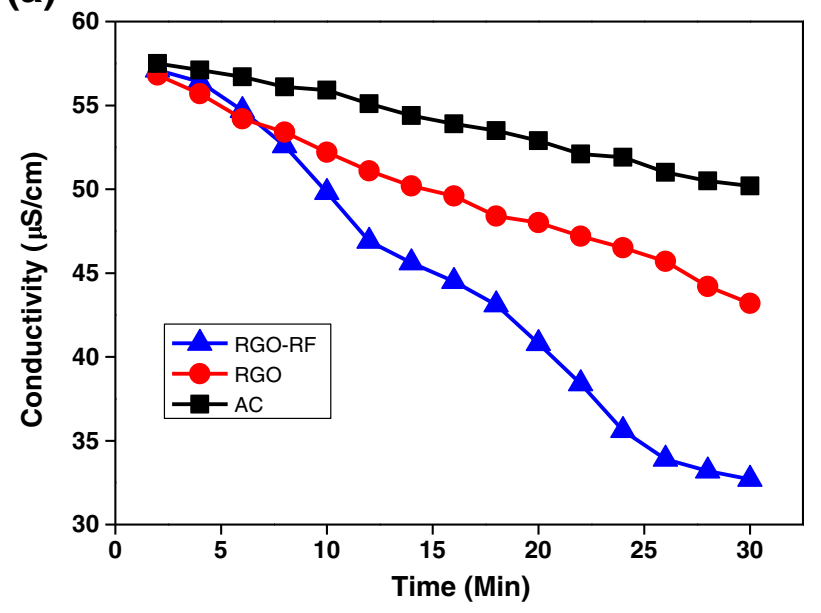

(b)

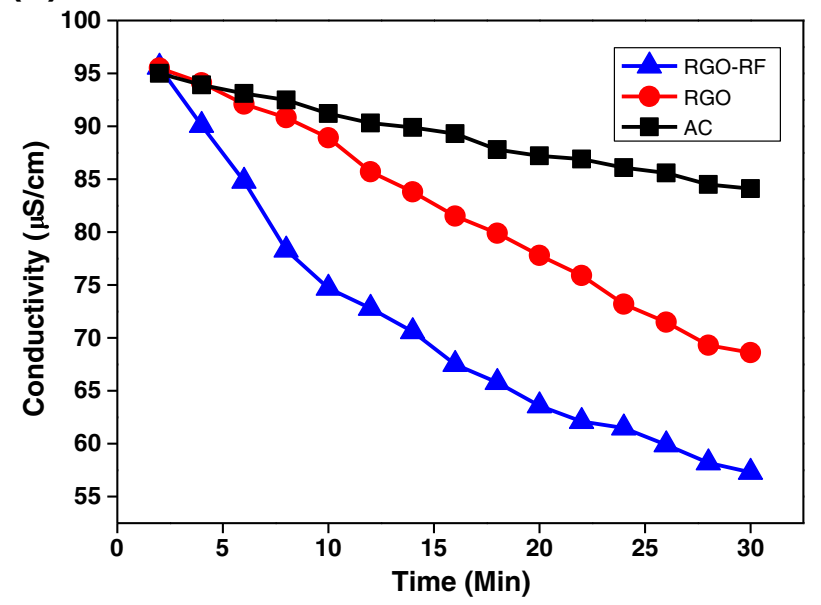

(c)

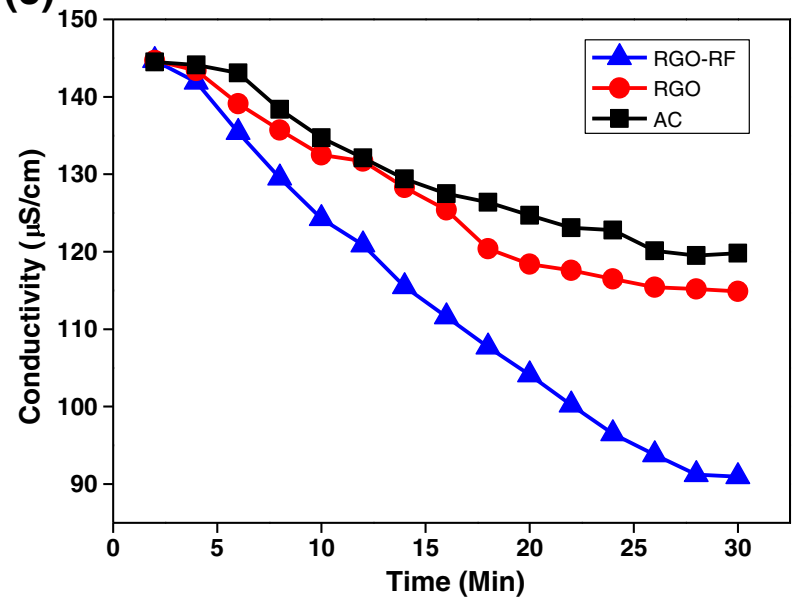

Fig. 6. Electrosorption of $\mathrm{NaCl}$ onto RGO-RF, RGO and AC electrode at voltage of $2.0 \mathrm{~V}$ and flow rate of $20 \mathrm{~mL} / \mathrm{min}$ with different initial concentrations: (a) $25 \mathrm{mg} / \mathrm{L}(57 \mu \mathrm{s} / \mathrm{cm})$, (b) $40 \mathrm{mg} / \mathrm{L}(95 \mu \mathrm{s} / \mathrm{cm})$ and (c) $65 \mathrm{mg} / \mathrm{L}(145 \mu \mathrm{s} / \mathrm{cm})$.

where $\mathrm{C}_{0}$ and $\mathrm{K}_{\mathrm{L}}$ are the initial concentration of $\mathrm{NaCl}$ and the Langmuir isotherm constant. If the value of $r<1$, it represents favourable adsorption while greater than 1.0 represents unfavourable adsorption. The value of $\mathrm{r}$ at initial $\mathrm{NaCl}$ concentration of $25 \mathrm{mg} / \mathrm{L}$ was found to be 0.79 , which indicates that the present system is favourable for adsorption.

Table 3 shows the determined parameters and regression coefficients $\mathrm{R}^{2}, \mathrm{~K}_{\mathrm{L}}$ and $\mathrm{K}_{\mathrm{F}}$ of Langmuir and Freundlich isotherms for RGO-
Table 2

Electrosorptive capacity in association with various electrodes under different initial concentrations.

\begin{tabular}{llll}
\hline Concentration & \multicolumn{2}{l}{ Electrode } & AC \\
\cline { 2 - 4 } & RGO-RF & RGO & $0.423 \mathrm{mg} / \mathrm{g}$ \\
\hline $25 \mathrm{mg} / \mathrm{L}$ & $1.424 \mathrm{mg} / \mathrm{g}$ & $0.799 \mathrm{mg} / \mathrm{g}$ & $0.612 \mathrm{mg} / \mathrm{g}$ \\
$40 \mathrm{mg} / \mathrm{L}$ & $2.135 \mathrm{mg} / \mathrm{g}$ & $1.510 \mathrm{mg} / \mathrm{g}$ & $1.507 \mathrm{mg} / \mathrm{g}$ \\
$65 \mathrm{mg} / \mathrm{L}$ & $3.229 \mathrm{mg} / \mathrm{g}$ & $1.800 \mathrm{mg} / \mathrm{g}$ & \\
\hline
\end{tabular}

based CDI, respectively. Fig. 7 presents the experimental data as well as the fitted line. It is clearly observed from Fig. 7 that the Langmuir isotherm correlated with the experimental data very well according to the correlation coefficient $\left(R^{2}\right)$. This suggested that the monolayer adsorption was primary during the electrosorption process. Furthermore, the parameter $\mathrm{Q}_{\mathrm{m}}$ defined as the maximum adsorption capacity is $13.245 \mathrm{mg} / \mathrm{g}$, implying the electrosorption limitations in RGO-RF electrode based on given experimental conditions. In addition, as introduced above, the $\mathrm{K}_{\mathrm{L}}$ related to the free energy is always employed to calculate the affinity between the electrosorbed species and electrode.

\subsection{Electrosorption kinetics}

Adsorption kinetics is an important characteristic of the adsorption process. The electrosorption rate of $\mathrm{NaCl}$ on RGO-RF was examined by studying the adsorption kinetics at different initial bias potential of $0.5 \mathrm{~V}, 1.0 \mathrm{~V}, 1.5 \mathrm{~V}$ and $2.0 \mathrm{~V}$ with a flow rate of $20 \mathrm{mg} / \mathrm{L}$. The kinetics of electrosorption and the electrosorption rate of $\mathrm{NaCl}$ were determined by the Lagergren equation, which is often called the pseudo-first-order adsorption kinetics (Eq. (6))

$\frac{d q_{t}}{d t}=k\left(q_{e}-q\right)$

where $\mathrm{k}$ is the adsorption rate constant $\left(\mathrm{min}^{-1}\right), \mathrm{q}_{\mathrm{e}}$ and $\mathrm{q}$ are the amount of $\mathrm{NaCl}$ adsorbed at equilibrium $(\mathrm{mg} / \mathrm{g}$ ) and time $\mathrm{t}(\mathrm{min})$, respectively. Integrating Eq. (6) with respect to the integration conditions of $\mathrm{q}=0$ to $\mathrm{q}=\mathrm{q}_{\mathrm{t}}$ at $\mathrm{t}=0$ to $\mathrm{t}=\mathrm{t}$, the kinetics rate expression becomes

$\log \left(q_{e}-q\right)=\log q_{e}-\frac{k t}{2.303}$

The adsorption kinetics was fitted with the Lagergren law by nonlinear regression using the method of least squares. The results are given in Fig. 8 and Table 4, and it is obvious that the adsorption capacity and the rate were increased greatly as the bias potential increased. The equilibrium adsorption capacity at $1.5 \mathrm{~V}$ was $1.002 \mathrm{mg} / \mathrm{g}$, while adsorption capacity at $2.0 \mathrm{~V}$ was increased to $1.735 \mathrm{mg} / \mathrm{g}$. However the regression coefficient $\mathrm{R}^{2}$ is smaller than it is at $1.5 \mathrm{~V}$, this maybe because of the quicker adsorption of $\mathrm{NaCl}$ on to the electrode at the beginning of the experiment. These results suggested that the maximum adsorption capacity for $\mathrm{NaCl}$ on RGO-RF electrode can be improved as the potential increased. Therefore, it was concluded that by using the RGO-RF electrodes the electrosorption could be effectively enhanced.

Table 3

Determined parameters and regression coefficients $\mathrm{R}^{2}, \mathrm{~K}_{\mathrm{L}}$ and $\mathrm{K}_{\mathrm{F}}$ of Langmuir and Freundlich isotherms of RGO-RF based CDI at room temperature.

\begin{tabular}{llll}
\hline Isotherm & Model equation & Parameter & Value \\
\hline Langmuir & $Q=\frac{Q_{m} K_{L} C}{1+K_{L} C}$ & $\mathrm{Q}_{\mathrm{m}}$ & 13.245 \\
& & $\mathrm{~K}_{\mathrm{L}}$ & 0.01072 \\
& & $\mathrm{R}^{2}$ & 0.9925 \\
Freundlich & $\mathrm{Q}=K_{\mathrm{F}} \mathrm{C}^{1 / n}$ & $\mathrm{~K}_{\mathrm{F}}$ & 2.2801 \\
& & $\mathrm{n}$ & 0.477 \\
& & $\mathrm{R}^{2}$ & 0.9546 \\
\hline
\end{tabular}


(a)

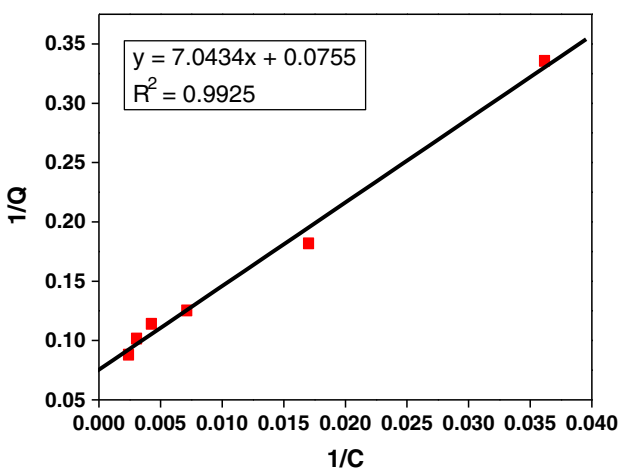

(b)

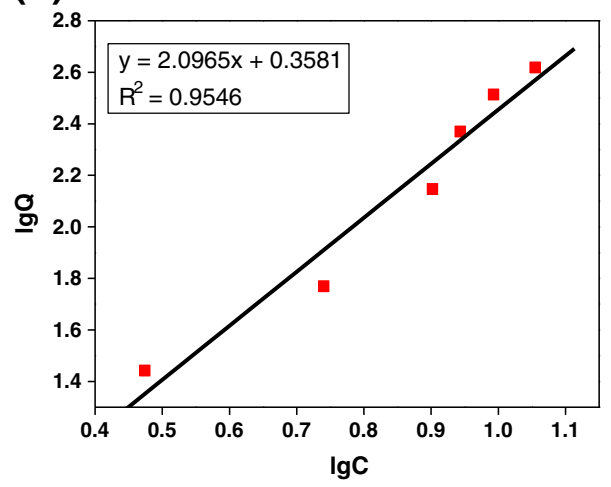

Fig. 7. Linearized electrosorption isotherms of $\mathrm{NaCl}$ onto RGO-RF electrode (a) Langmuir isotherm and (b) Freundlich isotherm at $2.0 \mathrm{~V}$.

\section{Conclusions}

In summary, the reduced graphite oxidate-resol like material (RGO-RF) was successfully synthesized and used as the electrodes for capacitive deionization (CDI). The RGO-RF composites show enhanced adsorption capacity for $\mathrm{NaCl}$ removal as compared with RGO. The addition of resol is beneficial for the increase of the specific surface area of reduced graphite oxidate (RGO), which results in high $\mathrm{NaCl}$ uptake. Furthermore, the electrosorptive behaviour of RGO-RF follows a Langmuir adsorption, illustrating a monolayer adsorption. The equilibrium electrosorption capacity and rate constant increased with the voltage at $1.5 \mathrm{~V}$ were $1.00234 \mathrm{mg} / \mathrm{g}$ and $0.05394 \mathrm{~min}^{-1}$, respectively. In conclusion, compared with $A C$ and the as-synthesized RGO, this RGO-RF material can be a candidate of electrode, which

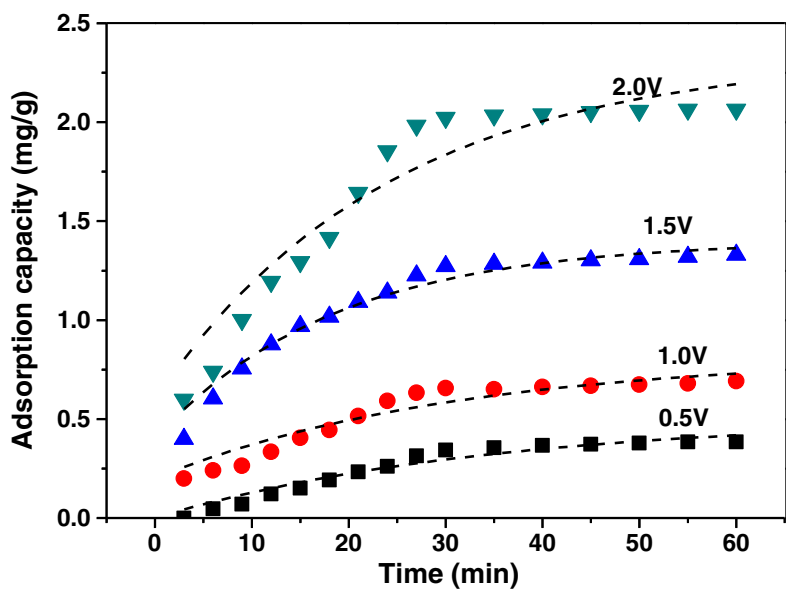

Fig. 8. Electrosorption kinetics of $\mathrm{NaCl}$ onto $\mathrm{RGO}-\mathrm{RF}$ at different bias potentials.
Table 4

Adsorption/electrosorption parameters of first-order adsorption kinetics for $\mathrm{NaCl}$ at different potentials.

\begin{tabular}{llll}
\hline Bias potentials $(\mathrm{V})$ & $\mathrm{qe}(\mathrm{mg} / \mathrm{g})$ & $\mathrm{K}\left(\times 10^{-2}\right)$ & $\mathrm{R}^{2}$ \\
\hline 0.5 & 0.5039 & 2.929 & 0.94917 \\
1.0 & 0.6185 & 3.216 & 0.91418 \\
1.5 & 1.0023 & 5.394 & 0.96607 \\
2.0 & 1.7353 & 4.147 & 0.92579 \\
\hline
\end{tabular}

shows a promising potential for efficient CDI process in brackish water desalination and drinking water purification.

Supplementary data to this article can be found online at http:// dx.doi.org/10.1016/j.desal.2012.05.028.

\section{Acknowledgements}

This work was financially supported by the National Natural Science Funds for Distinguished Young Scholar (20725723) and National Basic Research Program of China (2010CB732300).

\section{References}

[1] H.B. Li, L.D. Zou, L.K. Pan, Z. Sun, Novel graphene-like electrodes for capacitive deionization, Environ. Sci. Technol. 44 (2010) 8692-8697.

[2] H.B. Li, L.K. Pan, Y.P. Zhang, L.D. Zou, C.Q. Sun, Y.K. Zhan, Z. Sun, Kinetics and thermo dynamics study for electrosorption of $\mathrm{NaCl}$ onto carbon nanotubes and carbon nanofibers electrodes, Chem. Phys. Lett. 485 (2010) 161-166.

[3] M.T.M. Pendergast, E.M.V. Hoek, A review of water treatment membrane nanotechnologies, Energy. Environ. Sci. 4 (2011) 1946-1971.

[4] S. Wang, D.Z. Wang, L.J. Ji, Q.M. Gong, Y.F. Zhu, J. Liang, Equilibrium and kinetic studies on the removal of $\mathrm{NaCl}$ from aqueous solutions by electrosorption on carbon nanotube electrodes, Sep. Purif. Technol. 58 (2007) 12-16.

[5] L.D. Zou, L.X. Li, H.H. Song, G. Morris, Using mesoporous carbon electrodes for brackish water desalination, Water Res. 42 (2008) 2340-2348.

[6] E. Menachem, A.P. William, The future of seawater desalination: energy, technology, and the environment, Science 6043 (2011) 712-717.

[7] M. Al-Shammiri, M. Safar, Multi-effect distillation plants: state of the art, Desalination 126 (1999) 45-59.

[8] B. Pilat, Practice of water desalination by electro dialysis, Desalination 39 (2001) 385-392.

[9] H. Tanaka, T. Nosoko, T. Nagata, Parametric investigation of a basin-typemultiple-effect coupled solar still, Desalination 3 (2000) 295-304.

[10] Y.M. ElSayed, On the feasibility of large vapor-compression distillation units, Desalination 107 (1996) 13-27.

[11] Y.J. Kim, J.H. Choi, Enhanced desalination efficiency in capacitive deionization with anion-selective membrane, Sep. Purif. Technol. 71 (2010) 70-75.

[12] J.C. Farmer, D.V. Fix, G.V. Mack, R.W. Pekala, J.F. Poco, Capacitive deionization of $\mathrm{NaCl}$ and $\mathrm{NaNO}_{3}$ solutions with carbon aerogel electrodes, J. Electrochem. Soc. 143 (1996) 159-169.

[13] T.J. Welgemoeda, C.F. Schutte, Capacitive deionization technology: an alternative desalination solution, Desalination 83 (2005) 327-340.

[14] C.M. Yang, W.H. Choi, B.K. Na, B.W. Cho, W.I. Cho, Capacitive deionization of NaC1 solution with carbon aerogel-silica gel composite electrodes, Desalination 174 (2005) 125-133.

[15] M.S. Michael, S.R.S. Prabaharan, High voltage electrochemical double layer capacitors using conductive carbons as additives, J. Power. Sources 136 (2004) $250-256$.

[16] L. Li, H. Song, X. Chen, Ordered mesoporous carbons from the carbonization of sulfuric-acid-treated silica/triblock copolymer/sucrose composites, J. Microporous Mesoporous Mater. 94 (2006) 9-14.

[17] K. Dai, L.Y. Shi, D.S. Zhang, J.H. Fang, NaCl adsorption in multi-walled carbon nanotube/active carbon combination electrode, Chem. Eng. Sci. 61 (2006) 428-433.

[18] M. Ryoo, G. Seo, Improvement in capacitive deionization function of activated carbon cloth by titania modification, Water Res. 37 (2003) 1527-1534.

[19] J. Biener, M. Stadermann, M. Suss, M.A. Worsley, M.M. Biener, K.A. Rose, T.F. Baumann, Advanced carbon aerogels for energy applications, Energy Environ. Sci. 4 (2011) 656-667.

[20] C. Gabelich, T. Tran, A.H. Melsuffet, Electrosorption of inorganic salts from aqueous solution using carbon aerogels, Environ. Sci. Technol. 36 (2002) 3010-3019.

[21] H.B. Li, L.K. Pan, T. Lu, Y.K. Zhan, C.Y. Nie, Z. Sun, A comparative study on electrosorptive behavior of carbon nanotubes and graphene for capacitive deionization, J. Electroanal. Chem. 653 (2011) 40-44.

[22] M.A. Anderson, A.L. Cudero, J. Palma, Capacitive deionization as an electrochemical means of saving energy and delivering clean water. Comparison to present desalination practices: will it compete? Electrochim. Acta 55 (2010) 3845-3856. 
[23] R.T. Mayes, C. Tsouris, J.O. KiggansJr, S.M. Mahurin, D.W. Dai, S. DePaoliand, Hierarchical ordered mesoporous carbon from phloroglucinol-glyoxal and its application in capacitive deionization of brackish water, J. Mater. Chem. 20 (2010) 8674-8678.

[24] B. Yaniv, A. Eran, N. Malachi, M. Ben-Tzion, S. Abraham, A. Doron, Capacitive deionization of $\mathrm{NaCl}$ solutions at non-steady-state conditions: inversion functionality of the carbon electrodes, J. Phys. Chem. C 115 (2011) 16567-16573.

[25] S. Wang, D.Z. Wang, L.J. Ji, Q. Gong, Y.F. Zhu, J. Liang, Equilibrium and kinetic studies on the removal of $\mathrm{NaCl}$ from aqueous solutions by electrosorption on carbon nanotube electrodes, Sep. Purif. Technol. 58 (2007) 12-16.

[26] H. Li, L. Pan, Y. Zhang, L. Zou, C. Sun, Y. Zhan, Z. Sun, Kinetics and thermodynamics study for electrosorption of $\mathrm{NaCl}$ onto carbon nanotubes and carbon nanofibers electrodes, Chem. Phys. Lett. 485 (2010) 161-166.

[27] K.L. Yang, S. Yiacoumi, C. Tsouris, Electrosorption capacitance of nanostructured carbon aerogel obtained by cyclic voltammetry, J. Electroanal. Chem. 540 (2003) 159-167.

[28] Z. Chen, C. Song, X. Sun, H. Guo, G. Zhu, Kinetic and isotherm studies on the electrosorption of $\mathrm{NaCl}$ from aqueous solutions by activated carbon electrodes, Desalination 267 (2011) 239-243.

[29] K.S. Novoselov, A.K. Geim, S.V. Morozov, D. Jiang, Y.S. Zhang, V. Dubonos, I.V. Grigorieva, A.A. Firsov, Electric field effect in atomically thin carbon films, Science 306 (2004) 666-669.
[30] C.H. Lui, L. Liu, K.F. Mak, G.W. Flynn, T.F. Heinz, Ultra flat graphene, Nature 462 (2009) 339-341.

[31] S. Gilje, S. Han, M.S. Wang, K.L. Wang, R.B. Kaner, A chemical route to graphene for device applications, Nano Lett. 7 (2007) 3394-3398.

[32] X.S. Li, W.W. Cai, J.H. An, S. Kim, J. Nah, D.X. Yang, R. Piner, A. Velamakanni, I. Jung, E. Tutuc, S.K. Banerjee, L. Colombo, R.S. Ruoff, Large-area synthesis of high-quality and uniform graphene films on copper foils, Science 324 (2009) 1312-1314.

[33] M.D. Stoller, S.J. Park, Y.W. Zhu, J.B. An, R.S. Ruoff, Graphene-based ultracapacitors, Nano Lett. 8 (2008) 3498-3502.

[34] X.L. Li, X.R. Wang, L. Zhang, S.W. Lee, H.J. Dai, Chemically derived ultrasmooth graphene nanoribbon semiconductors, Science 319 (2008) 1229-1232.

[35] H.B. Li, L.D. Zou, L.K. Pan, Z. Sun, Using graphene nano-flakes as electrodes to remove ferric ions by capacitive deionization, Sep. Purif. Technol. 75 (2010) $8-14$.

[36] H.B. Li, T. Lu, L.K. Pan, Y.P. Zhang, Z. Sun, Electrosorption behavior of graphene in $\mathrm{NaCl}$ solutions, J. Mater. Chem. 19 (2009) 6773-6779.

[37] S. William, J. Hummers, R.E. Offeman, Preparation of graphitic oxide, J. Am. Chem. Soc. 80 (1958) 1339-1341.

[38] M.A. Worsley, P.J. Pauzauskie, T.Y. Olson, J. Biener Jr., J.H. Satcher, T.F. Baumann, Synthesis of graphene aerogel with high electrical conductivity, J. Am. Chem. Soc. 132 (2010) 14067-14069. 